\title{
Ultrastructural Analysis of Normal and Leukaemic Cells by the Immunogold Method and Monoclonal Antibodies*
}

\author{
E. Matutes and D. Catovsky
}

\section{A. Introduction}

Morphological and membrane marker analysis of the leukaemic cells are useful for the diagnosis and classification of human leukaemias. A combination of immunological and electron microscope (EM) techniques can now be carried out by using electron-dense tracers such as colloidal gold particles to visualise the reaction with a monoclonal antibody (MoAb)-immunogold method (IGM) [1]. Application of this technique has allowed the characterisation of distinct $T$ lymphocyte subpopulations in normal blood [2, 3]. In this study we analyse by this method the expression of various lineage-specific membrane antigens in normal haemopoietic precursor cells and in blast cells from patients with acute leukaemia and blast crisis from chronic granulocytic leukaemia (CGL) and myelofibrosis (MF) to see if a more precise characterisation of the immature cells can be made.

\section{B. Materials and Methods}

Peripheral blood and bone marrow samples from healthy donors and 16 leukaemic patients: 9 acute leukaemias and 7 blast crisis from CGL [3] and MF [4] were studied. Mononuclear cells were isolated by centrifugation on Lymphoprep (Nyegaard)

* MRC Leukaemia Unit, Royal Postgraduate Medical School, London W12 OHS, England and washed twice in phosphate-buffered saline (PBS).

\section{Monoclonal Antibodies}

The following MoAb were used: LICR LON/R10 (anti-glycophorin A) against erythroid precursors [4]; AN51, C15, C17 and $\mathrm{J} 15$ against platelet glycoproteins $\mathrm{Ib}$, IIIa and the complex IIb/IIIa [5, 6, 7]; My9 against myeloid precursors [8]; J5, anticALL antigen, to identify lymphoblasts [9] and 3C5 against myeloid and lymphoid precursors [10].

\section{Immunogold Staining}

A $200-\mu l\left(5 \times 10^{6}\right.$ cells $)$ volume was resuspended in PBS, $1 \%$ bovine serum albumin (BSA), $0.2 \%$ sodium azide. $2 \%$ human AB serum ( $\mathrm{pH}$ 7.4) and incubated with the relevant $\mathrm{MoAb}$ for $30 \mathrm{~min}$ at room temperature (RT). Cells were washed twice and incubated for $1 \mathrm{~h}$ at RT with $40 \mu \mathrm{l}$ goat anti-mouse IgG conjugated to $30-\mathrm{nm}$ colloidal gold particles (Janssen Life Sciences, Beerse, Belgium). After three washes, samples were processed for EM analysis following standard techniques. Controls were carried out by omitting the first layer MoAb or by using an irrelevant anti-mouse immunoglobulin. In several instances the following cytochemical reactions: myeloperoxidase (MPO), acid phosphatase (AP) and platelet peroxidase (PPO) were performed. 


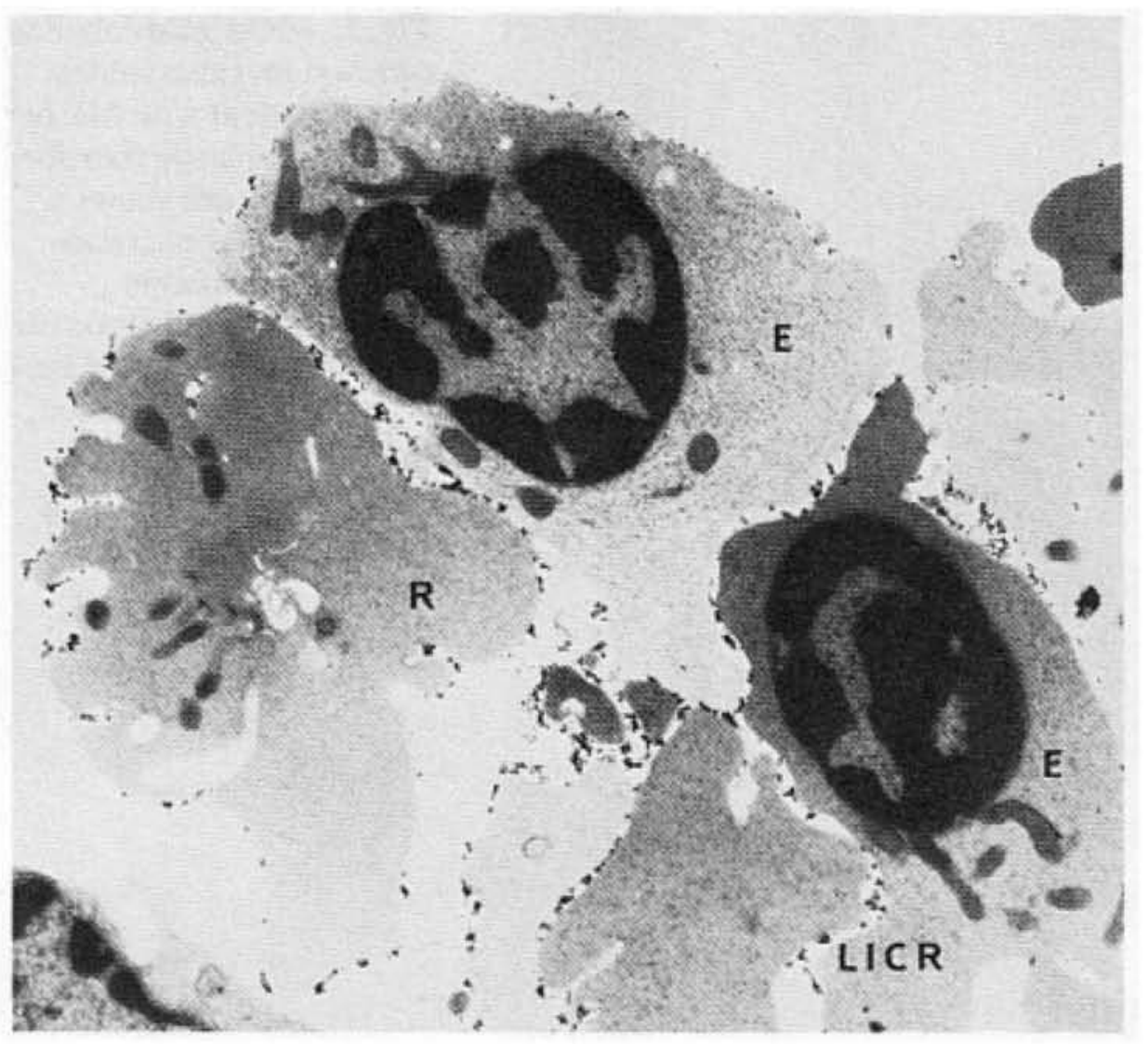

Fig. 1. Normal bone marrow erythroblasts (E) reactive with LICR anti-glycophorin A and heavily labelled with colloidal gold particles. Note the presence of a reactive reticulocyte

(R) (uranyl acetate and lead citrate stain, $\times 16000$ )

\section{Results}

\section{Erythroid}

A proportion of cells (22\% and 23\%) from two patients (one with erythroid blast crisis of CGL and one with erythroleukaemia) were seen gold labelled with LICR anti-glycophorin A. According to the morphological features, various stages of cell differentiation were identified in the reactive cells. Undifferentiated blasts were seen together with more mature cells which had specific features (e.g. siderosomes) of the erythroid lineage. AP activity when present, was localised in large lysosomal granules and/ or endoplasmic reticulum (ER) in both immature and mature erythroid cells. In normal bone marrow, the expression of LICR was demonstrated from proerythroblasts to reticulocytes and red blood cells (Fig. 1) $^{1}$. The degree of reactivity as judged by the number of gold particles in the cell membrane increased with cell maturation, both in normal and leukaemic samples.

1 In Figs. 1-6, unless otherwise stated, 30-nm colloidal gold particles conjugated to goat anti-mouse IgG were used

\section{Megakaryocytic}

Reactivity with the various anti-platelet $\mathrm{MoAb}$ was seen in cells from patients with CGL and MF in megakaryoblastic transformation. Blast cells having a "lymphoid" appearance (Fig. 2) in addition to cells with features of megakaryocytic differentiation (e.g. $\alpha$-granules) and giant platelets were identified by the gold labelling with the several MoAb used. In the differentiated cells, gold particles were distributed on the cell membrane and in the open canalicular system. The number of antigenic sites differed from one case to another, but a stronger staining was more frequently seen in the more mature cells and platelets.

\section{Myeloid}

Myeloblasts from four cases of acute leukaemia (three acute myeloid leukaemia and one mixed leukaemia-lymphoid and myeloid) displayed a different pattern of reactivity with the MoAb $3 \mathrm{C} 5$ and My9 when studied in combination with the MPO reaction. Myeloblasts that were MPO negative or with little MPO activity showed strong reaction with $3 \mathrm{C} 5$ (Figs. 3 and 4) 


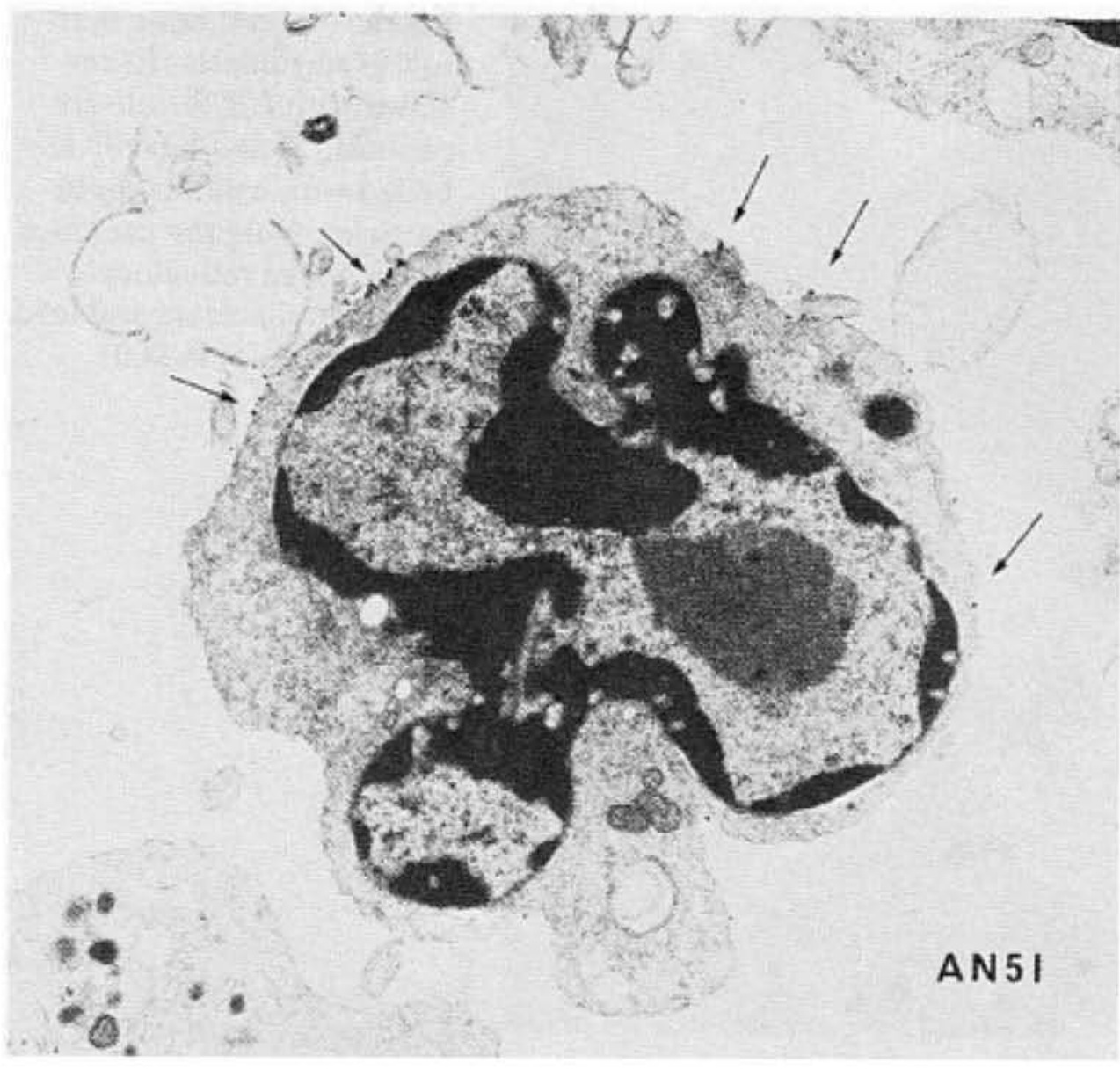

Fig. 2. AN51 gold-labelled (arrows) megakaryoblast from a patient with MF in megakaryoblastic transformation. The cell shows a "lymphoid" appearance without identifiable features of megakaryocytic differentiation (uranyl acetate and lead citrate stain, $\times 18000$ )

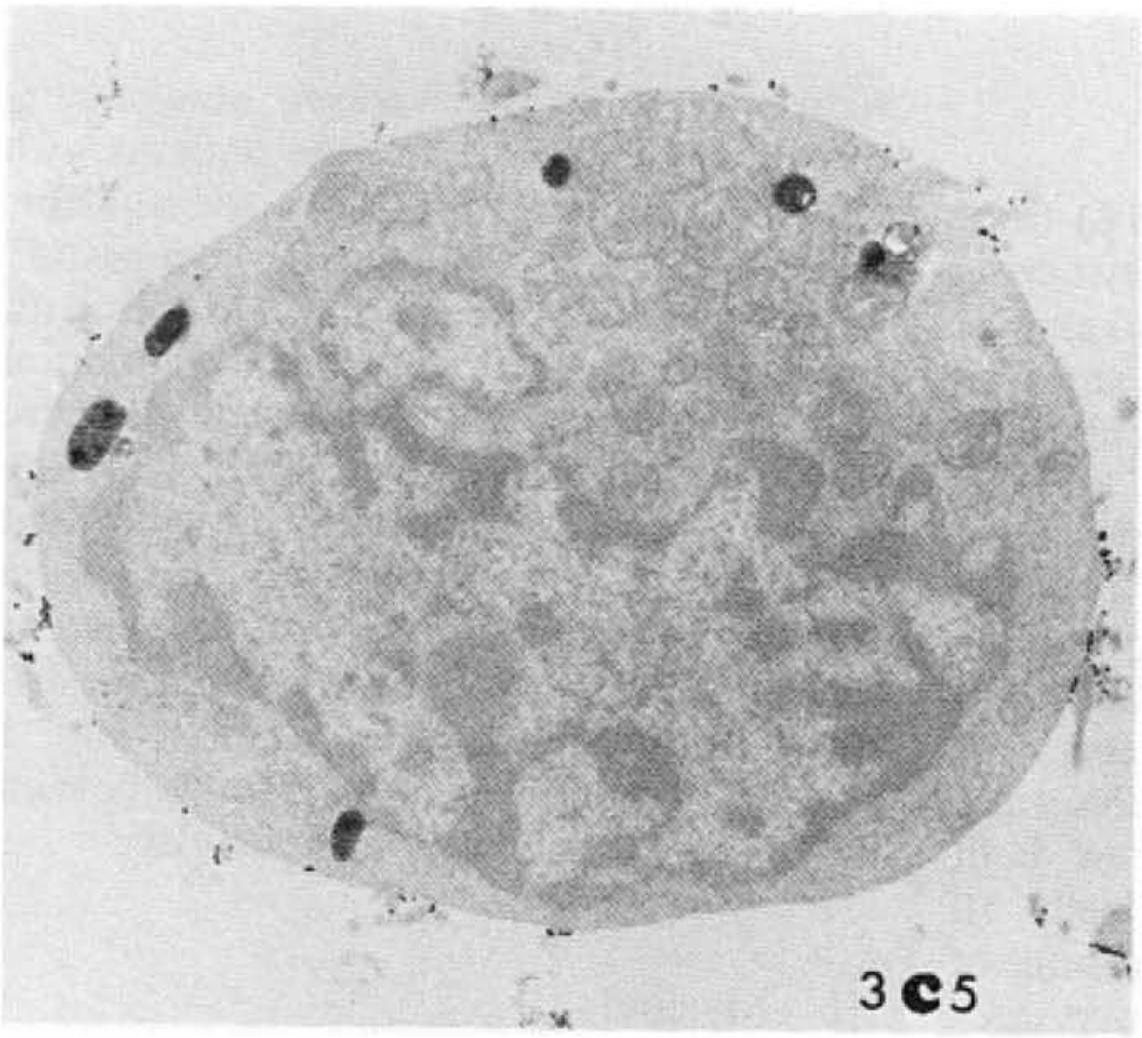

Fig. 3. 3C5 reactive blast from a patient with acute myeloid leukaemia, showing MPO activity localised in various granules (unstained section, $\times 16000$ )

and were either My9 positive or My9 negative, whereas the reactivity with My9 increased in parallel to the MPO content of the cells. Promyelocytes and myelocytes were also seen labelled with My9. This pattern was also observed in normal bone marrow although the degree of reactivity was lower in normal cells when compared with the leukaemic cells.

\section{Lymphoid}

Leukaemic cells from two patients with ALL and two CGL in lymphoid blast crisis 


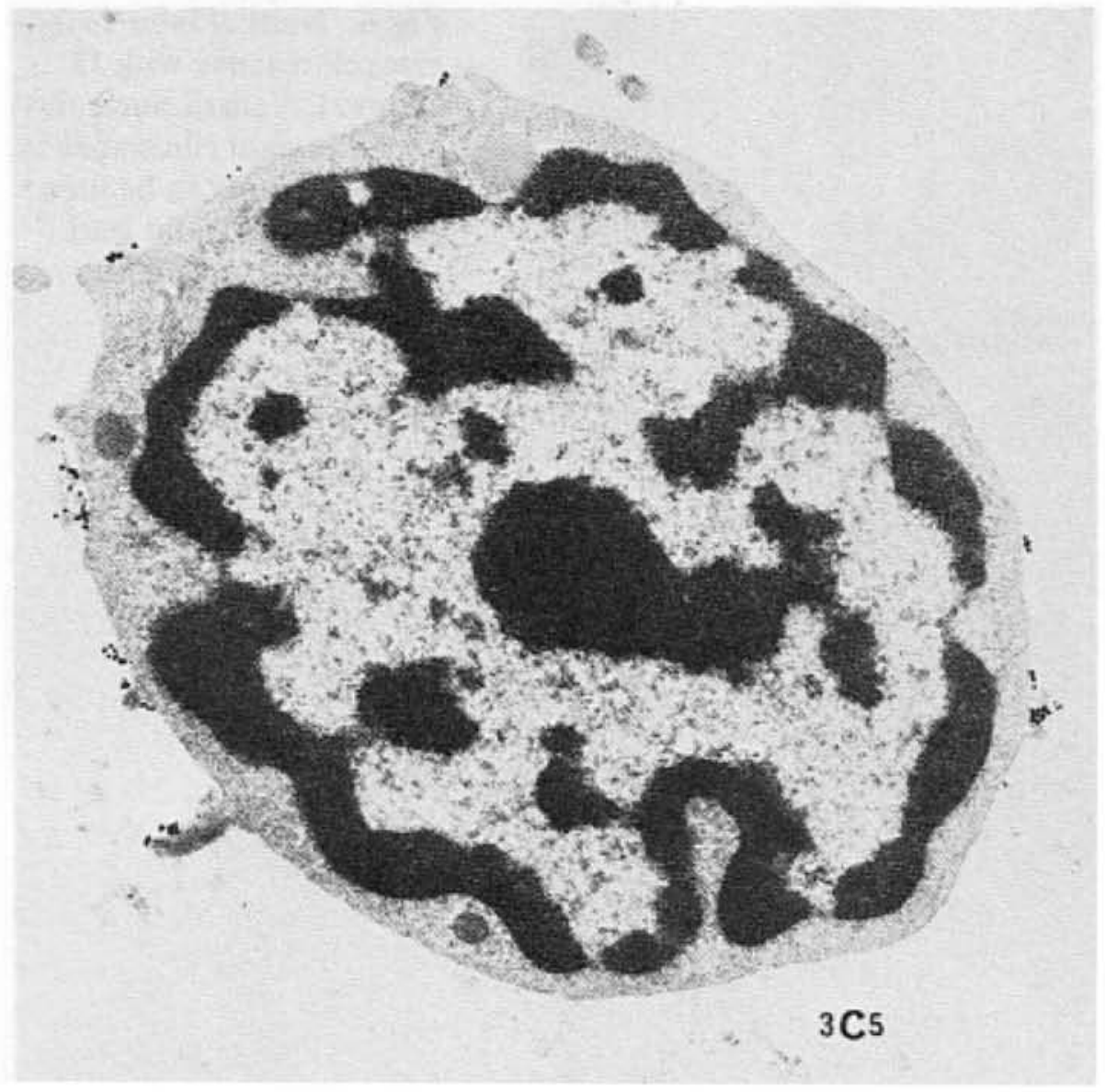

Fig. 4. 3C5-positive (gold labelled), MPO-negative blast from a patient with mixed acute leukaemia (My + Ly) showing a lymphoid morphology (uranyl acetate and lead citrate stain, $\times 18000$ )

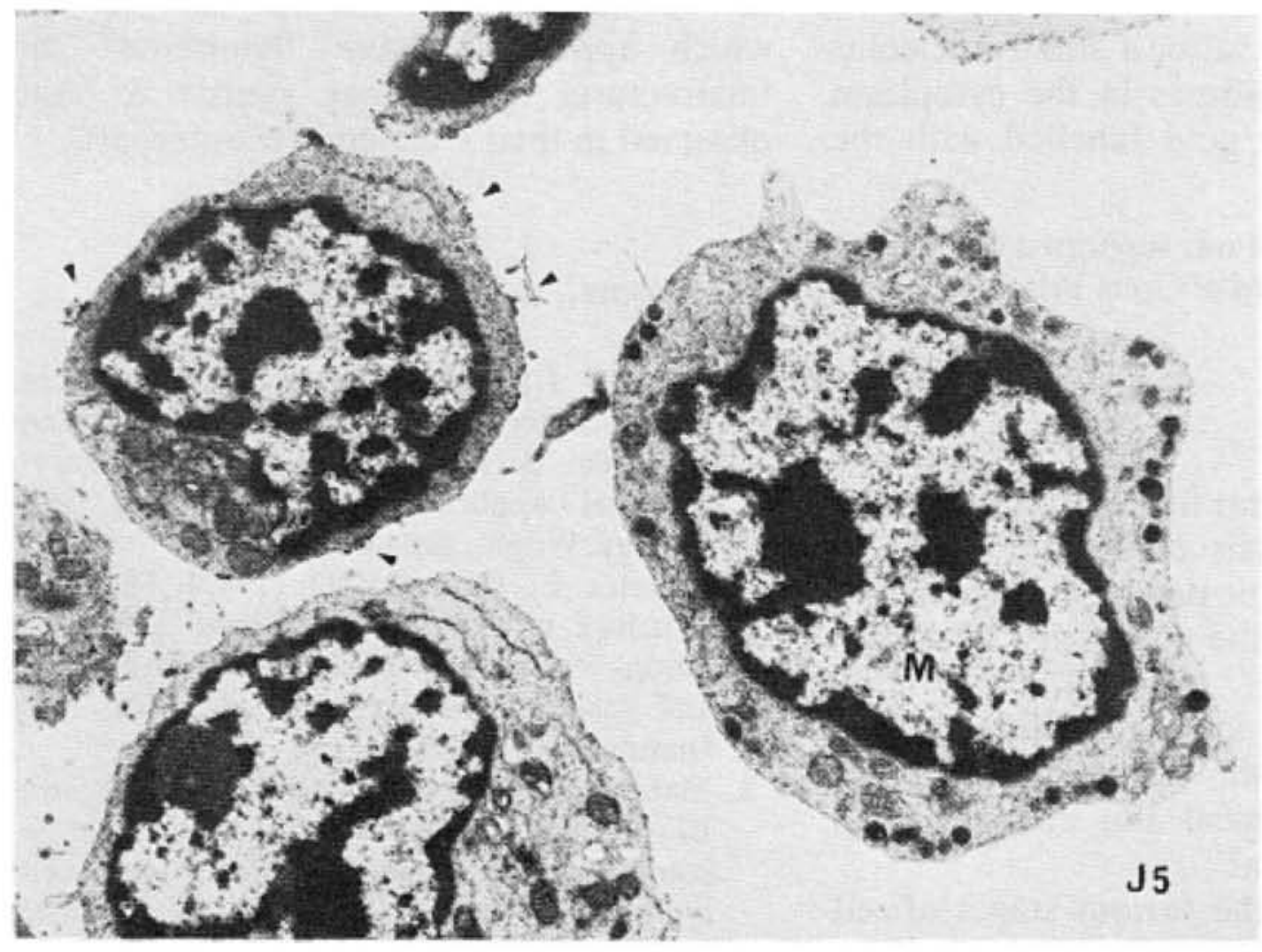

Fig. 5. J5-positive (labelled with 20-nm gold particles) (arrows) cell from a CGL-lymphoid blast crisis. Note the presence of a J5-negative (gold-unlabelled) myeloid cell (M) (uranyl acetate and lead citrate stain, $\times 10200$ ) were J5 positive. The specificity of the labelling could be assessed in the latter disease in which the remaining myeloid cells from the chronic phase were clearly J5 negative (Fig. 5). In normal bone marrow, a minority of small cells having a high 


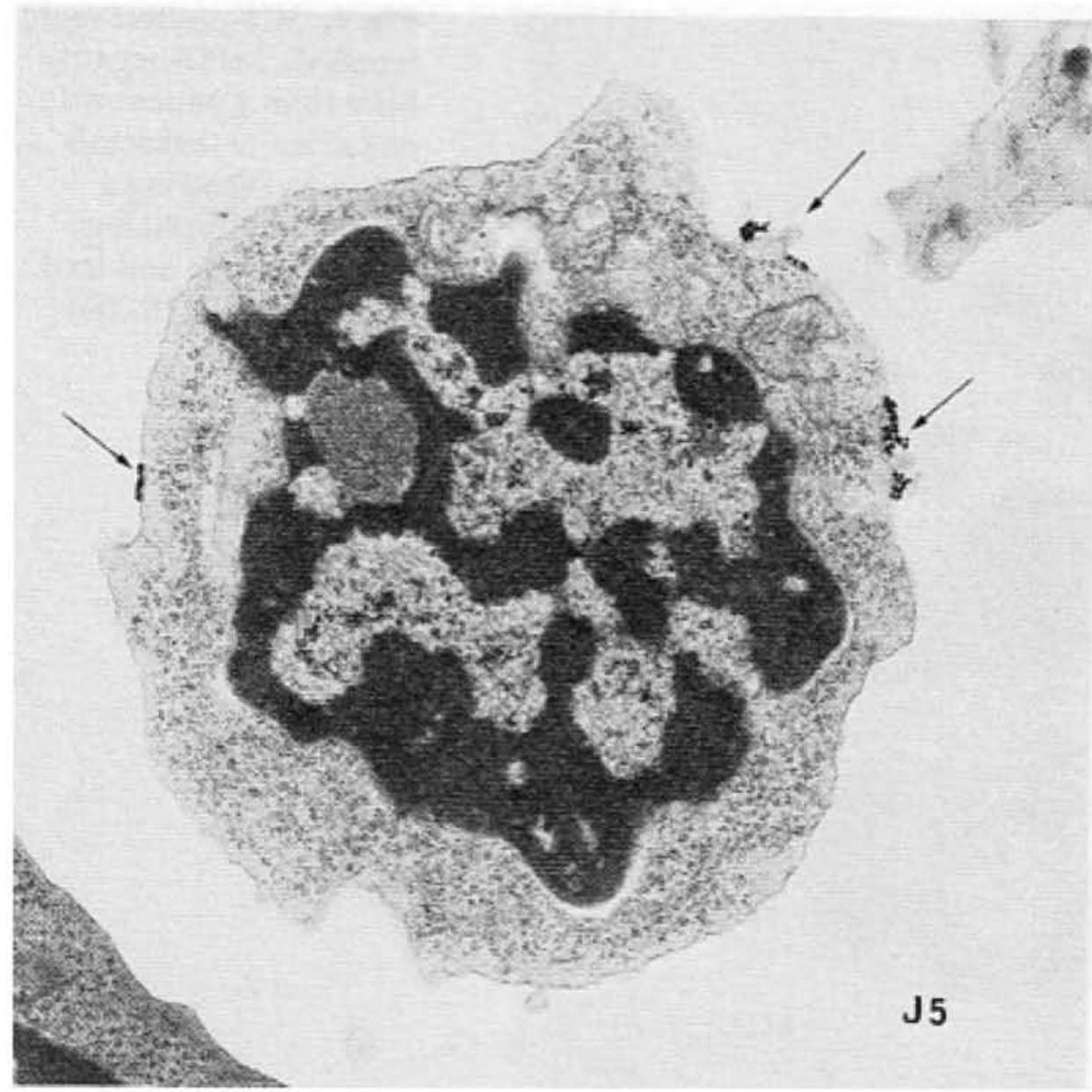

Fig. 6. Normal bone marrow cell reactive with $\mathrm{J} 5$ (arrows). A small nucleolus and abundant ribosomes in the cytoplasm can be seen (uranyl acetate and lead citrate stain, $\times 18000$ )

nucleocytoplasmic ratio, a small nucleolus and scattered ribosomes in the cytoplasm were identified as gold labelled with the MoAb J5 (Fig. 6).

Acknowledgment: EM was supported by the Leukaemia Research Fund of Great Britain.

\section{Conclusions}

This study shows that the application of the IGM in the analysis of normal and leukaemic haemopoietic precursors is useful:

1. To establish the specificity of a particular MoAb.

2. To determine in single cells the presence of two specific markers of differentiation: immunological and ultrastructural and/or cytochemical.

3. To recognise the various stages of cell maturation present in some acute leukaemias on the basis of their membrane phenotype and enzyme activity.

4. To characterise the different cell populations that proliferate in mixed leukaemias.

5. To identify normal bone marrow lymphoid and megakaryocytic precursors which appear to have "lymphoid" ultrastructural morphology similar to that observed in their leukaemic counterparts.

\section{References}

1. De Mey J (1983) Colloidal gold probes in immunocytochemistry. In: Polak JM, Van Noorden S (eds) Immunocytochemistry: practical applications in pathology and biology. Wright, Bristol, pp 82-112

2. Matutes E, Catovsky D (1982). The fine structure of normal lymphocyte subpopulations - a study with monoclonal antibodies and the immunogold technique. Clin Exp Immunol 50:416-425

3. Matutes E, Robinson D, O'Brien M, Haynes BF, Zola H, Catovsky D (1983) Candidate counterparts of Sézary cells and adult T-cell lymphoma leukaemia cells in normal peripheral blood: an ultrastructural study with the immunogold method and monoclonal antibodies. Leuk Res 7:878-892

4. Edwards PAW (1980) Monoclonal antibodies that bind to the human erythrocyte membrane glycoproteins glycophorin A and band 3. Biochem Soc Trans 8:334

5. McMichael AJ, Rust NA, Pilch J, Sochynsky R, Morton J, Mason DY, Ruan C, Tabelem 
G, Caen J (1981) Monoclonal antibody to human platelet glycoprotein I. I. Immunological studies. $\mathrm{Br}$ J Haematol 49:501 $-509$

6. Tetteroo PA, Lansdorp PM, Leeksma OC, $\mathrm{Kr}$ von dem Borne AEG (1983) Monoclonal antibodies against human platelet glycoprotein IIIa. Br J Haematol 55:509-522

7. Vainchenker $W$, Deschamps, $J$, Bastin $J$, Guichard J, Titeux M, Breton-Gorius J, McMichael A (1982) Two monoclonal antibodies as markers of human megakaryocyte maturation. Immunofluorescent staining and platelet peroxidase detection in megakaryocyte colonies and in vivo cells from normal and leukaemic patients. Blood 59:514-521

8. Griffin JD (1984) Expression of myeloid differentiation antigens in acute myeloblastic leukaemia. In: Bernard A, Boumsell L, Dausset J, Milstein C, Schlossman SF (eds) Leucocyte typing. Human leucocyte differentiation antigens detected by monoclonal antibodies. Springer, Berlin Heidelberg New York

9. Ritz J, Pesando J, Notis-McConarty J, Lazarus H, Schlossman SF (1980) A monoclonal antibody to human lymphoblastic leukaemic antigen. Nature 283:583-585

10. Tindle RW, Nichols RAB, Chan LC, Campana D, Catousky D, Birnie GD (1985) A novel monoclonal antibody BI-3C5 recognises myeloblasts and non-B non- $T$ lymphoblasts in acute leukaemias and CGL blast crises and reacts with immature cells in normal bone marrow. Leuk Res (in press) 